\title{
De-noise of Online Monitoring Basic Data Collected by Surveying Robots
}

\author{
http://dx.doi.org/10.3991/ijoe.v11i2.4476 \\ Wei Li ${ }^{1}$, Hongqi Xiong ${ }^{2}$, Houguang Sun ${ }^{2}$, Yachun $\mathrm{Mao}^{3^{*}}$, Hankang Zhang ${ }^{3}$ \\ ${ }^{1}$ University of Science and Technology Liaoning, Anshan, China \\ 2 Anqian Mining Co.Ltd, Anshan, China \\ ${ }^{3}$ Northeastern University, Shenyang, China
}

\begin{abstract}
Three-dimensional online monitoring systems based on a surveying robot (TCA2003) are widely used in the slope monitoring of various open pits. A lot of noise is contained in basic monitoring data (azimuth, vertical angle, distance) because of various factors. Thus, the accuracy of basic monitoring data is greatly reduced, and this issue has become a limitation in landslide warning. In this paper, multi-cycle monitoring data from multiple open pits are used as data source and de-noised using different filtering methods. At the same time, filtering effect is evaluated using the image and accuracy of filtered basic data. Best filtering methods of different monitoring basic data are proposed, laying the foundation for automated processing of monitoring data based on a surveying robot.
\end{abstract}

Index Terms-Slope monitoring, Surveying robot, Filtering, Accuracy

\section{INTRODUCTION}

In recent years, open pits have been greatly threatened by slope landslide incidents of different degrees that have happened in many domestic and international open pits. Many scholars have conducted in-depth studies on slope safety [1-6] and monitoring data processing [7, 8]. The recent local landslides at the open-pit iron mine and openpit coal mine in Liaoyang and Fushun, China, are shown in Figures 1 and 2. Figures 3 and 4 show the monitoring sites of the $3 \mathrm{D}$ monitoring system based on a surveying robot at the open-pit iron mine and open-pit coal mine in Liaoyang and Fushun. However, given the impact of internal and external factors in the monitoring process, a large amount of noise is found in the online monitoring basis data, which has become a challenge of early accuracy warning of landslides. Conventional mathematical methods, such as regression analysis, are usually used as preprocessing methods of basic online monitoring data based on surveying robots. However, because wavelet analysis has obvious advantages in terms of signal denoising, it has been widely used in the preprocessing of deformation online monitoring data in recent years [9-12].

In the present paper, multi-cycle actual online monitoring data are used as data source. Online monitoring data were filtered with the use of different wavelet basis, and different filtering effects were analyzed using pictures and accuracy. Better filtering methods have been developed, laying the foundation for automated processing of online monitoring data based on a surveying robot.

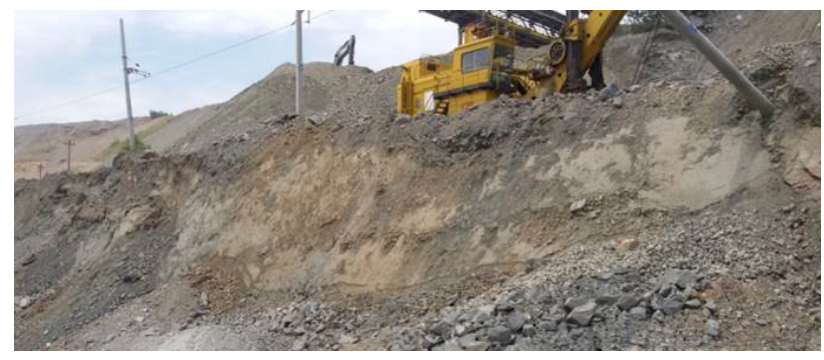

Figure 1. Local slope at the open-pit iron mine in Liaoyang

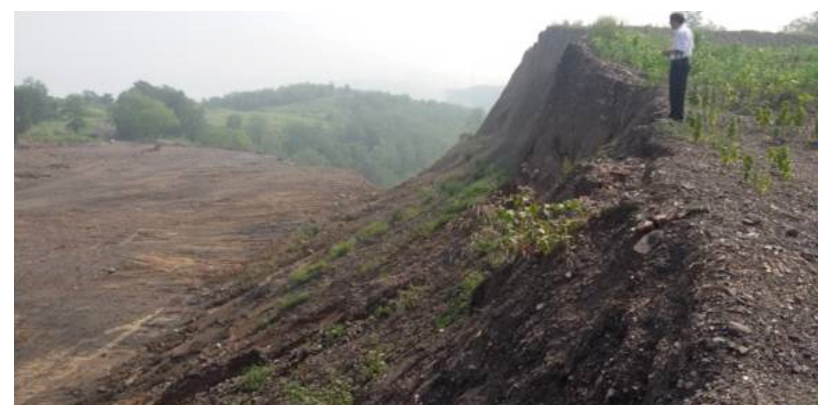

Figure 2. Local slope at the open-pit coal mine in Fushun

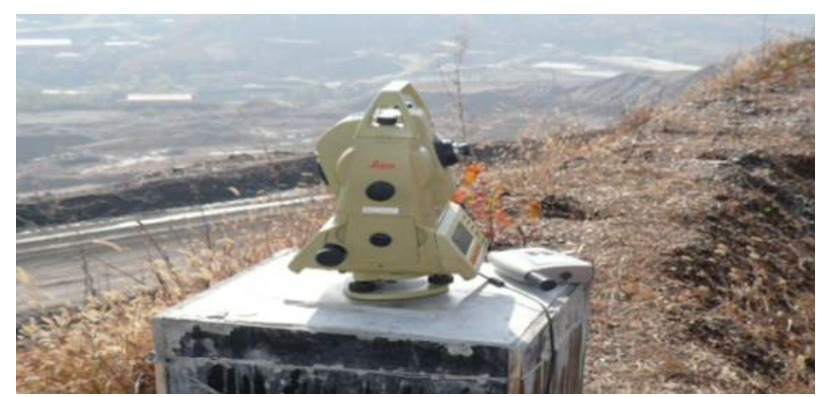

Figure 3. The Liaoyang open-pit iron mine

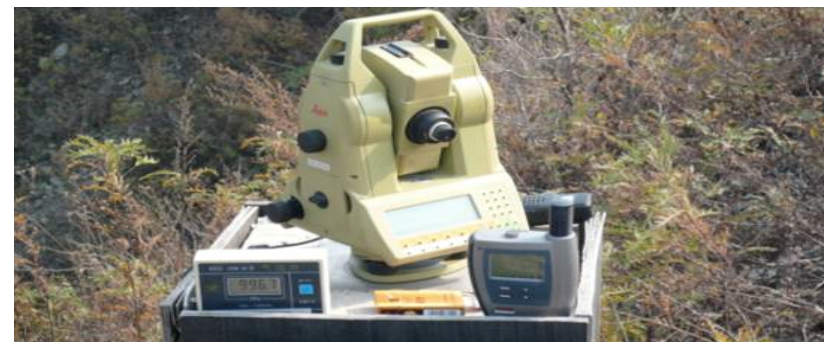

Figure 4. The Fushun open-pit coal mine 


\section{De-NOISING ANALYSIS OF BASIC ONLINE MONITORING DATA}

Basic data (azimuth, vertical angle, distance) on multiperiod online monitoring from the open-pit iron mine and open-pit coal mine in Liaoyang and Fushun, China, were used as the source. The noise was decreased through soft threshold, hard threshold, and compulsory de-noising methods. The best de-noising method for basic data based on surveying robots was summed up according to the filtering effect of the different filtering methods and different wavelet bases.

\section{A. Azimuth filtering and analysis}

\section{1) Soft threshold filtering and analysis}

The images of azimuth de-noising using soft threshold based on $\mathrm{db} 5, \mathrm{db} 4, \mathrm{db} 3$, and $\mathrm{db} 2$ wavelet bases are displayed in Figures 5 to 8 .

As shown in Figure 5, according to the comparative analysis of the filtering effect based on different wavelet ba-

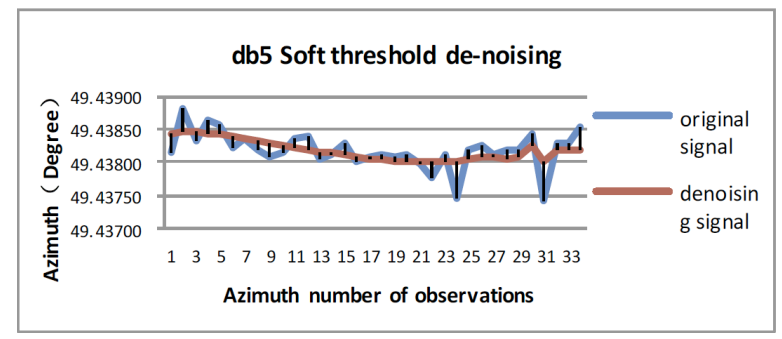

Figure 5. Azimuth db5 Soft threshold de-noising

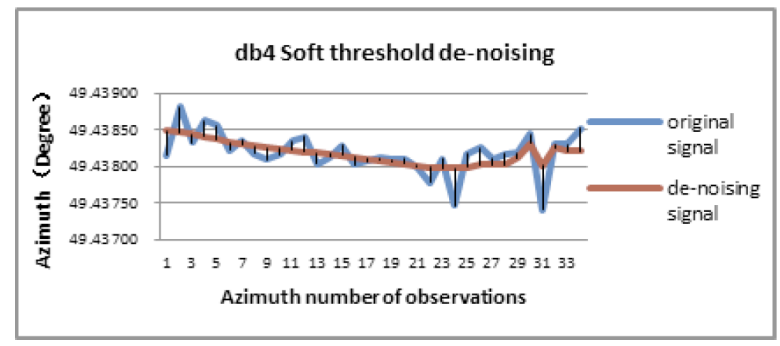

Figure 6. Azimuth db4 Soft threshold de-noising

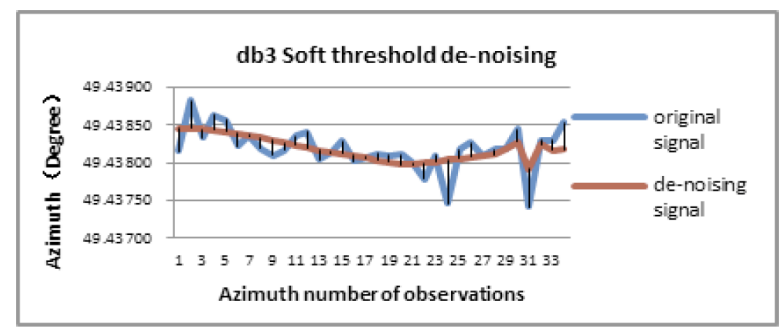

Figure 7. Azimuth db3 Soft threshold de-noising

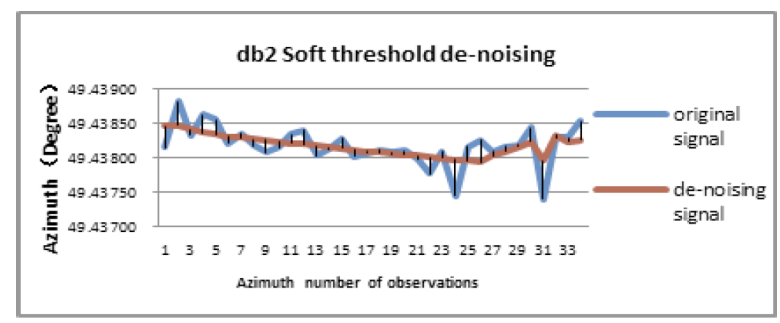

Figure 8. Azimuth db2 Soft threshold de-noising ses, the jump amplitude of the image waveform of the processed data by $\mathrm{db} 3$ is the smallest. The curve image processed by db5 wavelet is relatively smooth, but the jump amplitude is larger than the curve image processed by $\mathrm{db} 3$ wavelet and its data stability is relatively worse. The broken line phenomenon of a curve in the image processed by db2 wavelet is very obvious, and its jump amplitude is larger than the curve image processed by $\mathrm{db} 5$ wavelet, but smaller than that of db4 wavelet. The accuracy of the filtering data is determined by data stability, so a more stable filtering data is better. Results are shown through multi-period data filtering processing. In the condition of soft threshold de-noising of azimuth data, the wavelet basis order according to de-noising effect from good to poor is $\mathrm{db} 3, \mathrm{db} 5, \mathrm{db} 2$, and $\mathrm{db} 4$. However, of note is that $\mathrm{db} 5$ is better than $\mathrm{db} 3$ in very few cases.

2) Hard threshold filtering and analysis

Images of azimuth de-noising using hard threshold based on $\mathrm{db} 5, \mathrm{db} 4, \mathrm{db} 3$, and $\mathrm{db} 2$ wavelet bases are displayed in Figures 9 to 12.

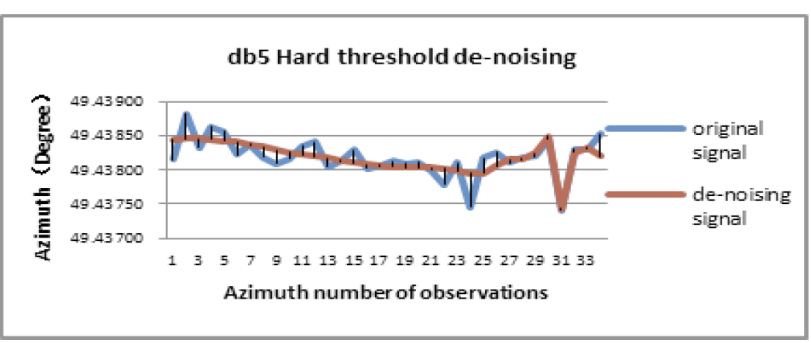

Figure 9. Azimuth db5 Hard threshold de-noising

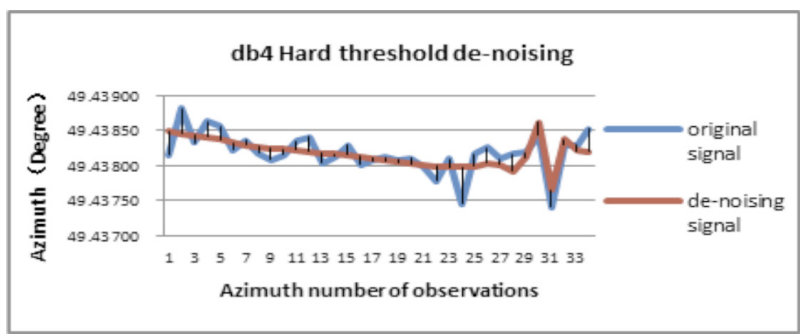

Figure 10. Azimuth db4 Hard threshold de-noising

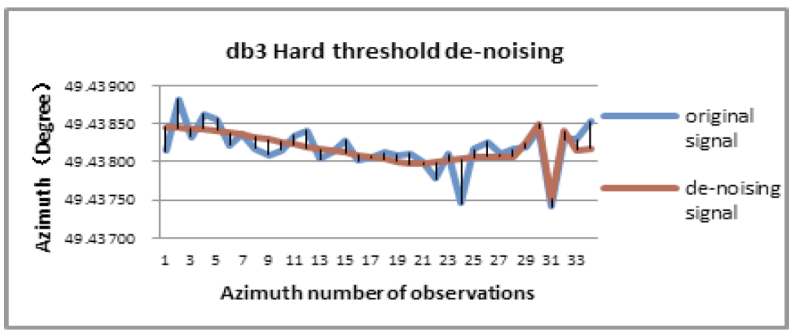

Figure 11. Azimuth db3 Hard threshold de-noising

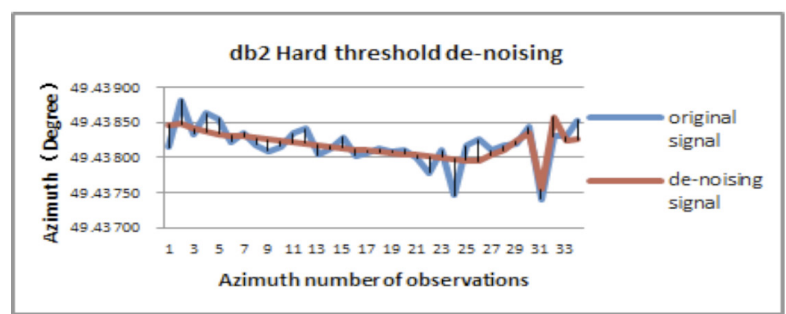

Figure 12. Azimuth db2 Hard threshold de-noising 
As shown in Figures 9 to 12, according to the comparative analysis of the filtering effect based on different wavelet bases, the conclusions of azimuth processed by hard threshold de-noising are the same with those processed by soft threshold de-noising, that is, the effect of $\mathrm{db} 3$ is the best, db5 is better than $\mathrm{db} 2$, and $\mathrm{db} 2$ is better than $\mathrm{db} 4$.

\section{3) Compulsory de-noising filtering and analysis}

The images of azimuth de-noising using compulsory de-noising based on $\mathrm{db} 5, \mathrm{db} 4, \mathrm{db} 3$, and $\mathrm{db} 2$ wavelet bases are displayed in Figures 13 to 16.

According to the comparative analysis of the effect of different wavelet bases filtering, the curve images of compulsory de-noising are the smoothest. However, the rules are the same for images processed by soft threshold and hard threshold; that is, the effect of db3 is the best, db5 is better than $\mathrm{db} 2$, and $\mathrm{db} 2$ is better than $\mathrm{db} 4$.

In summary, the effects of azimuth filtering processed by soft threshold, hard threshold, and compulsory denoising change with different wavelet bases. The wavelet basis order according to the de-noising effect from good to

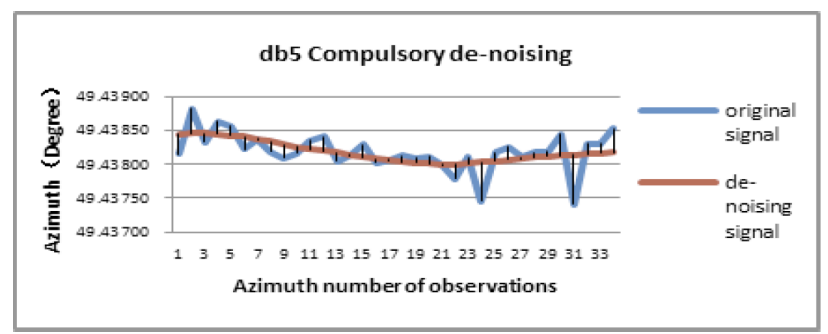

Figure 13. Azimuth db5 Compulsory de-noising

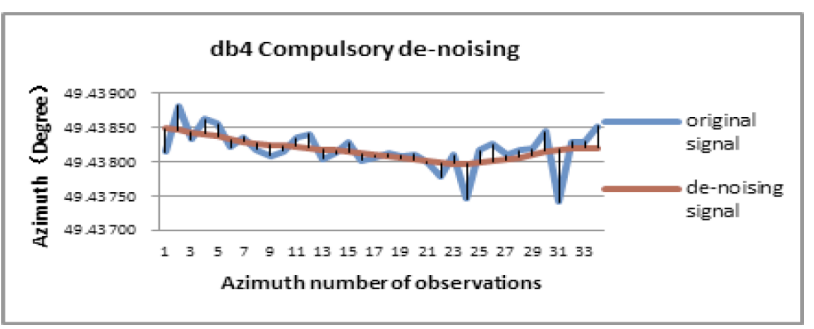

Figure 14. Azimuth db4 Compulsory de-noising

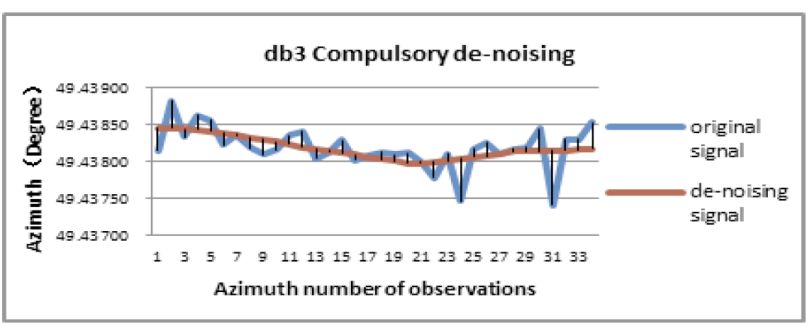

Figure 15. Azimuth db3 Compulsory de-noising

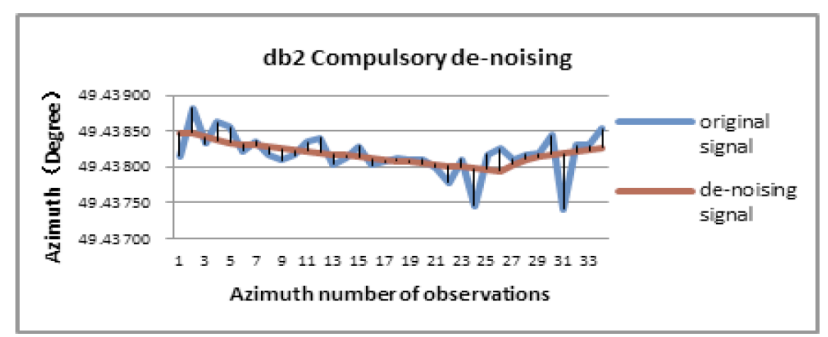

Figure 16. Azimuth db2 Compulsory de-noising poor is $\mathrm{db} 3, \mathrm{db} 5, \mathrm{db} 2$, and db4. Nonetheless, in very few cases, db5 is better than $\mathrm{db} 3$. In the three methods, images produced by compulsory de-noising and soft threshold denoising are smoother, and no obvious oscillation disturbance and broken line phenomenon were observed. Therefore, based on the analysis of the de-noising results, the effect of azimuth de-noising processed by $\mathrm{db} 3$ wavelet basis with soft threshold or compulsory de-noising is better. The same method is applied to the de-noising of vertical angles, and the conclusion is almost the same with that of azimuth de-noising.

\section{B. Distance filtering and analysis}

Distance is de-noising processed by soft threshold, hard threshold, and compulsory de-noising method based on $\mathrm{db} 5, \mathrm{db} 4, \mathrm{db} 3$, and $\mathrm{db} 2$ wavelet bases. According to the image analysis of filtering data, the wavelet basis order according to de-noising effect from good to poor is db5, $\mathrm{db} 2, \mathrm{db} 3$, and $\mathrm{db} 4$. In these three methods, the effect of compulsory de-noising and soft threshold de-noising based on db5 wavelet basis is much better.

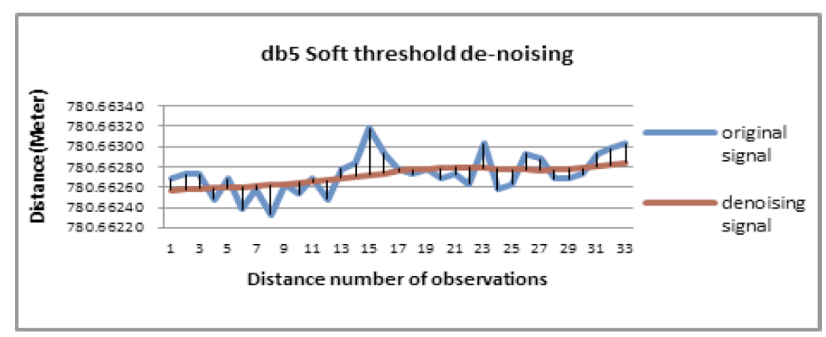

Figure 17. Distance db5 Soft threshold de-noising

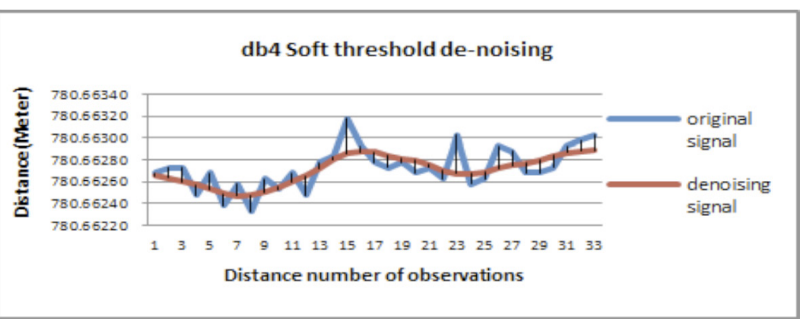

Figure 18. Distance db4 Soft threshold de-noising

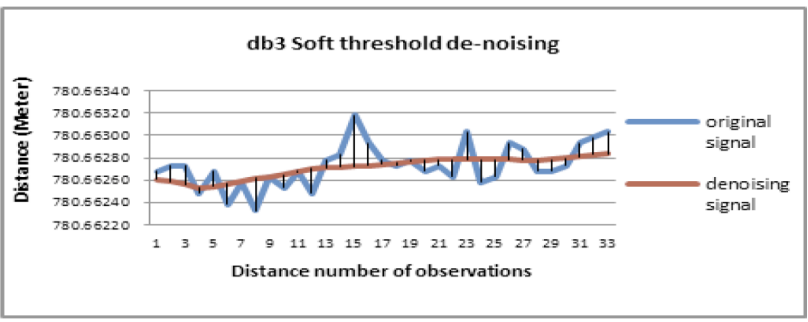

Figure 19. Distance db3 Soft threshold de-noising

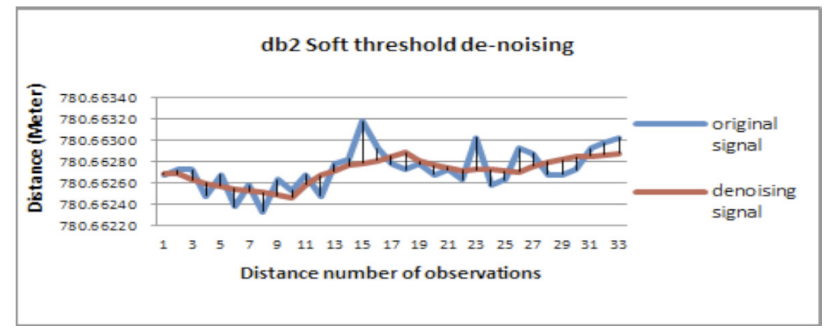

Figure 20. Distance db2 Soft threshold de-noising 


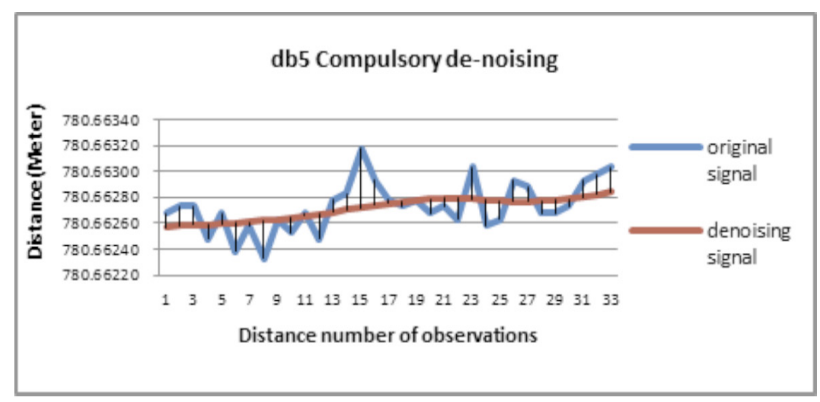

Figure 21. Distance db5 Compulsory de-noising

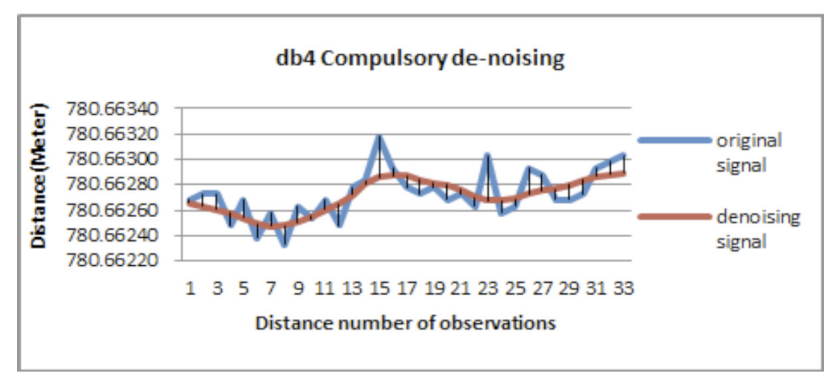

Figure 22. Distance db4 Compulsory de-noising

\section{Filtering ACCURACY ANALYSis Of ONLINE MONITORING BASIC DATA}

Filtering is an effective method for de-noising, but this method still has drawbacks depending on the analysis of waveform images. In this paper, multi-period online monitoring data were processed using different wavelet basis and de-noising methods. Different de-noising online monitoring data were acquired, and the accuracy of the de-noising data was evaluated using the following formula:

$$
m= \pm \sqrt{\frac{[V V]}{n-1}}
$$

where $\mathrm{m}$ is the mean square error of the data, $\mathrm{v}$ is corrections, and $\mathrm{n}$ is the number of measured values. The results of the accuracy evaluation are shown in Tables 1 to 3.

In Table I, the accuracy of azimuth de-noising by compulsory de-noising is higher than that by soft threshold denoising, whereas the accuracy of soft threshold de-noising is higher than that by hard threshold de-noising. At the same time, different wavelet bases have an important impact on the effect of de-noising. According to the results of multi-period processed data, the effect of compulsory de-noising and soft threshold de-noising based on $\mathrm{db} 3$ wavelet basis is much better for azimuth data.

In Table II, the accuracy of vertical angle data by compulsory de-noising is the same as that for soft threshold de-noising. The accuracy of the two is both higher than hard threshold de-noising. The effect of compulsory denoising and soft threshold de-noising based on db3 wavelet basis is the best for vertical angles.

In Table III, the accuracy of distance data by compulsory de-noising and soft threshold de-noising is almost the same. The accuracy of the two is higher than hard threshold de-noising. The effect of compulsory de-noising and soft threshold de-noising based on db5 wavelet basis is the best for distance data.

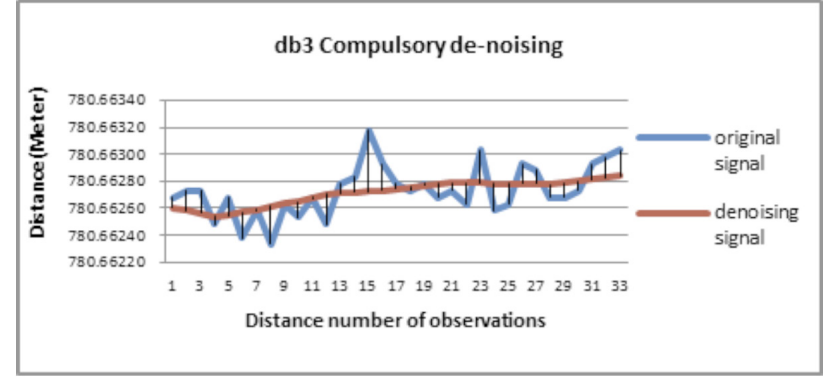

Figure 23. Distance db3 Compulsory de-noising

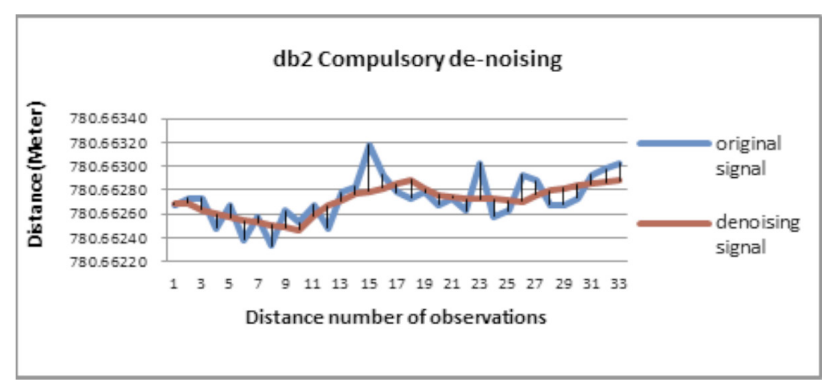

Figure 24. Distance db2 Compulsory de-noising

TABLE I.

ACCURACY COMPARISON OF AZIMUTH DE-NOISING

\begin{tabular}{lcccc}
\hline De-noising Method & \multicolumn{4}{c}{ soft threshold } \\
\hline Wavelet basis & $\mathrm{db} 5$ & $\mathrm{db} 4$ & $\mathrm{db} 3$ & $\mathrm{db} 2$ \\
\hline $\begin{array}{l}\text { The mean square } \\
\text { Error }( \pm \text { Second })\end{array}$ & 0.384 & 0.394 & 0.383 & 0.391 \\
\hline De-noising Method & \multicolumn{4}{c}{ hard threshold } \\
\hline $\begin{array}{l}\text { The mean square } \\
\text { Error ( } \pm \text { Second) }\end{array}$ & 0.412 & 0.424 & 0.407 & 0.423 \\
\hline De-noising Method & \multicolumn{5}{c}{ compulsory decreasing noise } \\
\hline $\begin{array}{l}\text { The mean square } \\
\text { Error }( \pm \text { Second })\end{array}$ & 0.383 & 0.392 & 0.380 & 0.388 \\
\hline
\end{tabular}

TABLE II.

ACCURACY COMPARISON OF VERTICAL ANGLES DE-NOISING

\begin{tabular}{lcccc}
\hline De-noising Method & \multicolumn{4}{c}{ soft threshold } \\
\hline Wavelet basis & $\mathrm{db} 5$ & $\mathrm{db} 4$ & $\mathrm{db} 3$ & $\mathrm{db} 2$ \\
\hline $\begin{array}{l}\text { The mean square } \\
\text { Error }( \pm \text { Second })\end{array}$ & 0.546 & 0.557 & 0.545 & 0.557 \\
\hline De-noising Method & \multicolumn{5}{c}{ hard threshold } \\
$\begin{array}{l}\text { The mean square } \\
\text { Error }( \pm \text { Second) }\end{array}$ & 0.579 & 0.583 & 0.571 & 0.591 \\
\hline De-noising Method & compulsory decreasing noise \\
$\begin{array}{l}\text { The mean square } \\
\text { Error }( \pm \text { Second })\end{array}$ & 0.546 & 0.557 & 0.545 & 0.556 \\
\hline
\end{tabular}

TABLE III.

ACCURACY COMPARISON OF DISTANCE DE-NOISING

\begin{tabular}{lllll}
\hline De-noising Method & \multicolumn{4}{c}{ soft threshold } \\
\hline Wavelet basis & $\mathrm{db} 5$ & $\mathrm{db} 4$ & $\mathrm{db} 3$ & $\mathrm{db} 2$ \\
\hline $\begin{array}{l}\text { The mean square } \\
\text { Error ( } \pm \text { Second) }\end{array}$ & 0.246 & 0.249 & 0.248 & 0.248 \\
\hline De-noising Method & \multicolumn{4}{c}{ hard threshold } \\
\hline $\begin{array}{l}\text { The mean square } \\
\text { Error ( } \pm \text { Second) }\end{array}$ & 0.249 & 0.256 & 0.254 & 0.254 \\
\hline De-noising Method & compulsory decreasing noise \\
\hline $\begin{array}{l}\text { The mean square } \\
\text { Error ( } \pm \text { Second) }\end{array}$ & 0.246 & 0.249 & 0.248 & 0.248 \\
\hline
\end{tabular}




\section{CONCLUSION}

In this paper, basic multi-period online monitoring data (azimuth, vertical angles, distance) were used as data sources. Basic monitoring data based on a surveying robot were filtered. The images and the accuracy of the filtered data were then analyzed. The main conclusions are as follows:

(1) The analysis results of images and accuracy of denoised azimuth monitoring data show that compulsory denoising is better than soft threshold de-noising and that soft threshold de-noising is better than hard threshold denoising. The wavelet order according to de-noising effect from good to poor is $\mathrm{db} 3, \mathrm{db} 5, \mathrm{db} 2$, and $\mathrm{db} 4$.

(2) The analysis results of images and accuracy of monitoring data of de-noised vertical angles show that the effect of compulsory de-noising and soft threshold denoising is the same. The two are better than hard threshold de-noising. The wavelet order according to de-noising effect from good to poor is $\mathrm{db} 3, \mathrm{db} 5, \mathrm{db} 2$, and $\mathrm{db} 4$.

(3) The analysis results of images and accuracy of denoised distance monitoring data show that the effects of compulsory de-noising and soft threshold de-noising are the same. The two are better than hard threshold denoising. The wavelet order according to de-noising effect from good to poor is $\mathrm{db} 5, \mathrm{db} 2, \mathrm{db} 3$, and $\mathrm{db} 4$.

Although the use of compulsory de-noising is slightly better than other methods, it may cause the unnecessary loss of characteristic signal. Soft threshold de-noising is used to remove the highest frequency noise and useful information in low frequency is retained. To achieve good de-noising effect, soft threshold is often used in daily data processing.

\section{ACKNOWLEDGMENT}

This research has been supported jointly by the National Natural Science Foundation (NNSF) of China (41371437) and the Cooperation Projects of Angang Mining Co. Ltd., Anshan (Anqian Mining Co. Ltd., Anshan )

\section{REFERENCES}

[1] D.A. Liu, Z.F. Yang, C.H. Tang, J. Wang and Y. Liu, "An automatic monitoring system for the shiplock slop of Wuqiangxi Hydropower Station," Engineering Geology, vol. 76,no.1-2, pp. 7991, 2004. http://dx.doi.org/10.1016/j.enggeo.2004.06.007

[2] Y.Q. Zhao, "A New Type of Automatic Monitoring System of Static and Dynamic Displacement on Dam and Slop," Procedia Engineering, 2012, vol. 43, pp. 387-392. http://dx.doi.org/10.1016/j.proeng.2012.08.067

[3] M. Peng, X.Y. Li, D.Q. Li and S.-H. Jiang, L.M. Zhang, "Slop safety evaluation by integrating multi-source monitoring information," Structural Safety, vol. 49, no.S1, pp. 65-74, 2013.

[4] N.W. Xu, C.A. Tang, L.C. Li, Z. Zhou, C. Sha, Z.Z. Liang and J.Y. Yang "Microseismic monitoring and stability analysis of the left bank in Jinping first stage hydropower station in southwestern China," International Journal of Rock Mechanics and Mining Sciences,vol.48, no.6, pp. 950-963,2011. http://dx.doi.org/10.1016/ j.ijrmms.2011.06.009
[5] V. Gruber, R. Marcelino and J.B. Silva, "Technology PLC-Power line communication used in monitoring systems online," International Journal of Online Engineering,vol.9, no.S1, pp. 22-25,2013. http://dx.doi.org/10.3991/ijoe.v9iS1.2233

[6] W.-S. Mei, Z.L. Zhang, B.M. Guo, et al, "Study on system of deformation monitoring system with robotic total station," Journal of Wuhan University, vol.27, no.2, pp. 165-171, 2002.

[7] Y.C. Mao, E.D. Wang and C.H. Xiu, "A new method data caper method for rejecting the deformation monitoring data with the gross errors," Journal of Northeastern University, vol.32, no.7, pp. 1020-1023, 2011.

[8] Y.C. Mao, Y. S. Chen, S.H. Wang and R. Betoubert, "Model of Gross Error Elimination for Monitoring Data Collected by A Surveying Robot," Journal of Engineering Science and Technology Review, vol.7, no.4,pp. 13-17, 2014.

[9] S. Kaewpijit, J.L. Moigne and T. Ei-Ghazawi, "Automatic reduction of hyperspectral imagery using wavelet spectral analysis," IEEE Transactions on Geoscience and Remote Sensing, vol.41, no.4, pp. 863-871, 2003. http://dx.doi.org/10.1109/TGRS.2003. $\underline{810712}$

[10] D.L. Donoho and L. Johnstone, "Ideal Spatial Adaptation by Wavelet Shrinkage," Biometrika, vol.81, no.3, pp. 425-455, 1994. http://dx.doi.org/10.1093/biomet/81.3.425

[11] O. Rioul and M. Vetterli, "Wavelets and signal processing," IEEE Signal Processing Magzine, vol.8, no.4, pp. 14-38, 1991. http://dx.doi.org/10.1109/79.91217

[12] K. Tao and J.J. Zhu, "A Hybrid Indicator for Determining the best Decomposition Scale of Wavelet De-noising," Acta Geodaetica et Cartographica Sinica, vol.41, no.5,pp. 749-755, 2012.

\section{AUTHORS}

Wei Li is a professor at the Institute for Geoinformatics \& Digital Mine Research, School of Civil Engineering, University of Science and Technology Liaoning, China. His research interests include theories and key technologies of digital mining, 3D geological modeling, and mine surveying technology (ln_as_1w@163.com)

Hongqi Xiong is a senior mining engineer at Anqian Mining Co. Ltd., Anshan, China. His research interests include theories and key technologies of digital mining (shguang2008@sina.com).

Houguang Sun is a mining engineer at Anqian Mining Co. Ltd., Anshan, China. His research interests include theories and key technologies of digital mining (shguang2008@sina.com).

Yachun Mao*, corresponding author, is a professor in the Institute for Geo-informatics \& Digital Mine Research, School of Resources \& Civil Engineering, Northeastern University, China. His research interests include theories and key technologies of digital mining, 3d geological modeling, and the technology of $3 \mathrm{~S}$ integration, mine surveying and mapping technology (dbdxmyc@163.com).

Hankang Zhang is a graduate student at School of Resources \& Civil Engineering, Northeastern University, China.(780460157@qq.com).

Submitted 15 February 2015. Published as resubmitted by the authors 10 March 2015. 